\title{
Appraisal of Antioxidative Strategies in the Erythrocytes of Marwari Sheep during Extreme Ambiences
}

\author{
Deeksha $^{1} *$ and Nalini Kataria ${ }^{2}$
}

Department of Veterinary Physiology, College of Veterinary and Animal Science, Rajasthan University of Veterinary and Animal Sciences, Bikaner 334001, India

*Corresponding author

\begin{abstract}
A B S T R A C T
Keywords

Marwari Sheep,

Antioxidative

strategies,

Antioxidants, LDH, G6PDH

Article Info

Accepted:

07 January 2019

Available Online:

10 February 2019

The present investigation was carried out for appraisal of antioxidative strategies in the erythrocytes of Marwari sheep during moderate, hot and cold ambiences. In each ambience, animals were categorized as male, female, 6-12 months, 12-18 months and 1824 months. Haemolysates were prepared to determine enzymes of antioxidative strategies. Enzymes of antioxidative strategies included glucose-6-phosphate dehydrogenase (G6PDH) and lactate dehydrogenase (LDH). Effect of extreme hot and cold ambiences was observed on both indicators of antioxidative strategies in the erythrocytes of Marwari sheep. The mean values of LDH in erythrocytes were significantly $(\mathrm{p} \leq 0.05)$ higher during hot and cold ambiences as compared to moderate mean value. The mean values were significantly $(\mathrm{p} \leq 0.05)$ higher in male animals in all the ambiences for G6PDH and was higher in females for LDH. The mean values of G6PDH in erythrocytes were significantly $(\mathrm{p} \leq 0.05)$ lower during hot ambience and significantly $(\mathrm{p} \leq 0.05)$ higher during cold ambience as compared to moderate mean value. Age effect showed a significant $(\mathrm{p} \leq 0.05)$ increase in the mean values of all the indicators being highest in the sheep of 18-24 months of age.
\end{abstract}

\section{Introduction}

Antioxidative strategies are present inside the cells in the form of various endogenous antioxidative enzymes, antioxidants and free radical scavengers. Imbalance in oxidant status of the cell can cause oxidative stress affecting both cellular and biological damages. Thus, it is reasonable to counterbalance oxidative stress by modulating reactive oxygen species production. Erythrocytes are constantly subjected to oxidative stress, from their role as an oxygen transporter. Oxygen can be converted to hydrogen peroxide by superoxide dismutase. Erythrocytes with normal glucose-6phosphate dehydrogenase (G6PDH) enzyme activity have higher pentose phosphate pathway activity compared to G6PDH deficient RBCs. Erythrocytes are therefore considered to be the perfect model to study the oxidative status of the blood because they are the preferable target of oxidative modification. Exposure to high concentrations 
of oxygen radicals, the lack of nucleus and mitochrondria, inability to synthesise new protein and degradation of detoxifying enzymes makes red blood cells uniquely vulnerable to oxidative stress. The mature erythrocytes retain an array of enzymes, proteins, carbohydrates, lipids, anions and cations, all of which are required in balance, for effective metabolism and functioning of the cell. An important consequence of an imbalance between the erythrocytes's components is the poor ability to cope with oxidative stress, which can result in degenerative changes in haemoglobin, cell membrane and enzymes required for normal erythrocytic function.

Analyses of oxidative stress can be useful in assessing the immune status of the animals during stress period as reactive oxygen species are used by the immune system as a way to attack and kill pathogens. Biochemical procedures carried out in blood cells are considered to be minimally invasive peripheral markers (Gutierrez et al., 2006).Indicators of oxidative stress allow the assessment of real status of physiological defenses and prevention of the appearance of correlated pathologies (Piccione et al., 2007).

Marwari breed of sheep constitutes a major portion of the sheep population in Western part of Rajasthan and plays an important role in the economy of arid and semi- arid tract. Recurring droughts, low rainfall and scanty vegetation modulate the physiological mechanisms of these animals to the extent of various pathologies. Changes in enzymes necessary for physiological adjustments are brought about by great fluctuations in ambient temperatures during extreme ambiences. The outcome of long exposure of sheep to extreme ambiences including extreme hot and cold is generally the oxidative stress, which does not show any clinical sign. Therefore, the present investigation was planned for the appraisal of antioxidative strategies in the erythrocytes of Marwari sheep during extreme ambiences.

\section{Materials and Methods}

Three hundred and sixty blood samples of apparently healthy Marwari sheep of both sexes ageing 6 months to 24 months were collected from private slaughter houses in and around Bikaner district, Rajasthan during moderate, hot and cold ambiences.

Blood samples were collected during slaughtering. In each ambience 120 blood samples were collected and the animals were grouped into male (60) and female (60). Moderate ambience comprised of OctoberNovember; hot ambience of May and June and cold ambience of December-January. To assess the effect of hot and cold ambiences on the parameters of antioxidative strategies in the erythrocytes of Marwari sheep, the result of various parameters analysed was compared with those analysed during moderate months serving as control. Following indicators were analysed to appraise the antioxidative strategies in erythrocytes:

Glucose-6-phosphate

dehydrogenase (G6PDH)

Lactate Dehydrogenase

Various computer programmes were used to determine means and standard error

(http://www.miniwebtool.com) and analyses of variance (www.danielsoper.com) to test the significance of the effects of ambiences, sex and age groups and correlations (Kaps and Lamberson, 2004). The changes in the means were measured by using multiple mean comparison procedures. For this Duncan's new multiple range test was used (Duncan, 1955). 


\section{Results and Discussion}

\section{Glucose-6-phosphate (G6PDH)}

\section{dehydrogenase}

The mean overall value of G6PDH in erythrocytes of Marwari sheep during moderate ambience (control) was 5.00 \pm 0.04

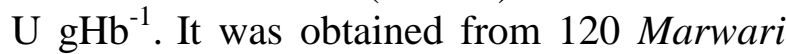
sheep irrespective of sex and age. The mean values of G6PDH in erythrocytes were significantly $(\mathrm{p} \leq 0.05)$ lower during hot ambience and significantly $(\mathrm{p} \leq 0.05)$ higher during cold ambience as compared to moderate overall mean value (Fig. 1). A highly significant $(\mathrm{p} \leq 0.01)$ effect of variation in ambience was also observed by analysis of variance.

These results corroborated the earlier findings carried out by Chaturvedi (2011) in goats for G6PDH status in erythrocytes. The lower concentration of this enzyme in hot ambience indicated its antioxidant type role which showed the depletion in an attempt to fight with free radicals. The enzyme G6PDH is considered as one of the enzymes associated with antioxidant defense. Variation in the activity during hot and cold ambiences reflected that cells were well equipped to defend from oxidative insult (Kempel et al., 1999). Aslan et al., (2005) found that climate had significant effects on blood G6PDH levels in lambs. Hot and cold ambiences probably worked as stressors which initiated adaptive responses (Kataria and Kataria, 2005). Defense against stress is also dependent upon G6PDH activity (Ercal et al., 2002), as stress can depress red blood corpuscles and leucocyte functions (Roley and Loegering, 1999). The sex and age effects were significant $(\mathrm{p} \leq 0.05)$ in moderate, extreme hot and cold ambiences (Fig. 2). The mean values were significantly $(p \leq 0.05)$ higher in female animals than male animals in all the ambiences. Age effect showed a significant $(\mathrm{p} \leq 0.05)$ increase in the mean values being highest in the sheep of 18-24 months of age. Highly significant $(p \leq 0.01)$ sex and age effects were revealed by analysis of variance.

Results corroborated the earlier findings (Chaturvedi, 2011). Eguinoa et al., (2003) also suggested higher G6PDH activity in heifers than bull. Age may change G6PDH activity (Nesse and Williams, 1998). Ozturk and Gumuslu (2004) also observed the age influence on G6PDH activity in rats. Glucose6-phosphate dehydrogenase is a key enzyme that regulates cellular redox potential. Since glutathione represents a cellular protectant against oxidative damage, which inhibits apoptosis,

\section{Lactate dehydrogenase (LDH)}

The mean overall value of LDH in erythrocytes of Marwari sheep during moderate ambience (control) was $30.90 \pm 0.11$

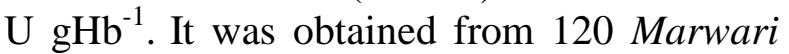
sheep irrespective of sex and age. The range of LDH in the present study corroborated the value given by Yagi et al., (1988) for bovine and by Chaturvedi (2011) for goat erythrocytes.

The mean values of LDH in erythrocytes were significantly $(\mathrm{p} \leq 0.05)$ higher during hot ambience and cold ambiences as compared to moderate overall mean value (Fig. 3). A highly significant $(\mathrm{p} \leq 0.01)$ effect of variation in ambience was also observed by analysis of variance. These results corroborated the earlier findings carried out by Chaturvedi (2011) in goats for G6PDH status in erythrocytes. Activity of this enzyme is known to increase under the condition of oxidative stress during the lipid peroxidation process. Subsequently that leads to the increase level of the lactic acid and lactic acid salts (Jovanovic et al., 2010). 
Fig.1 Mean changes in glucose-6-phosphate dehydrogenase (U gHb-1, G6PDH) overall values in the erythrocytes of Marwari sheep during extreme ambiences

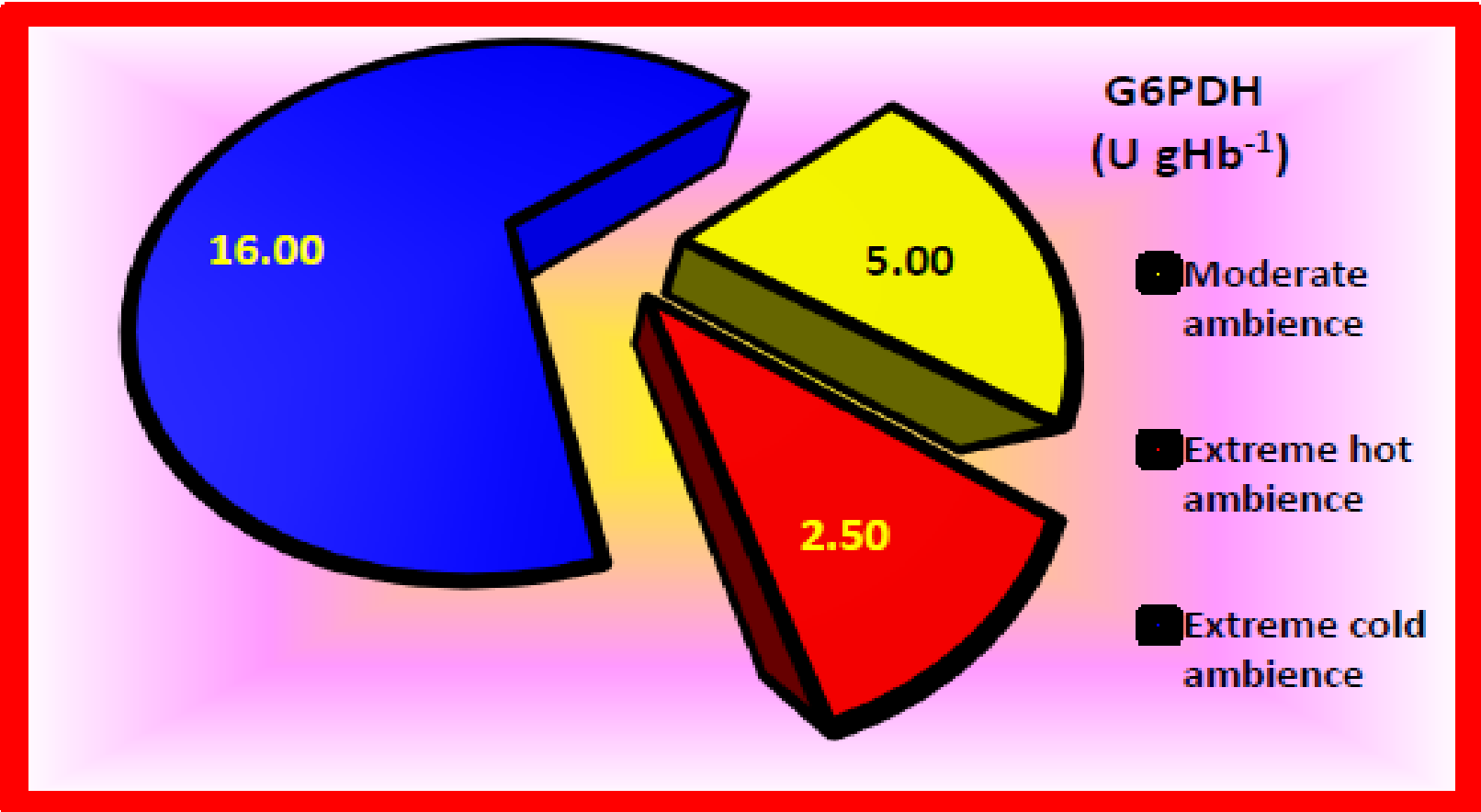

Fig.2 Mean changes in glucose-6-phosphate dehydrogenase (U gHb-1, G6PDH) values according to sex and age groups in the erythrocytes of Marwari sheep during extreme ambiences

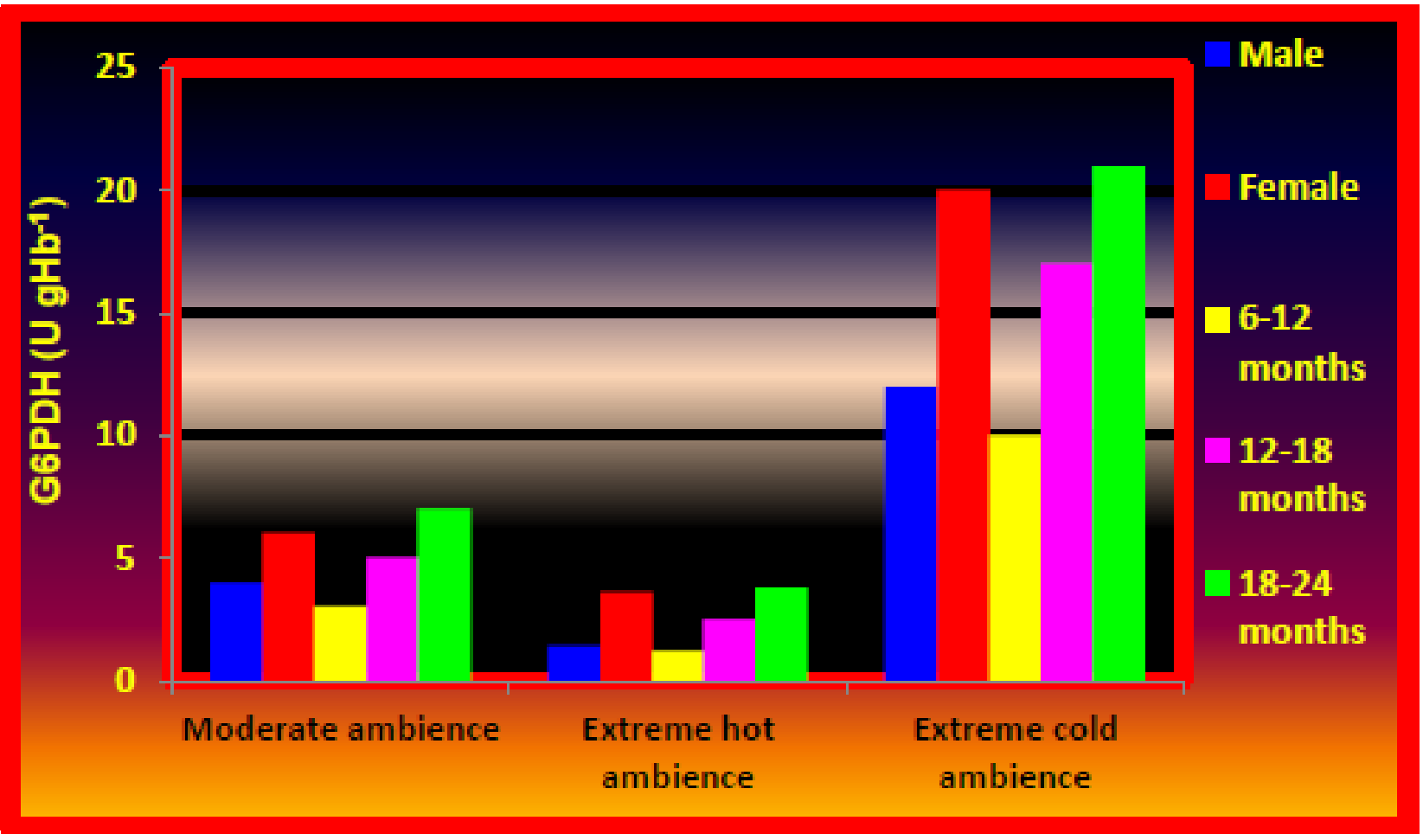


Fig.3 Mean changes in lactate dehydrogenase (U gHb-1, LDH) overall values in the erythrocytes of Marwari sheep during extreme ambiences

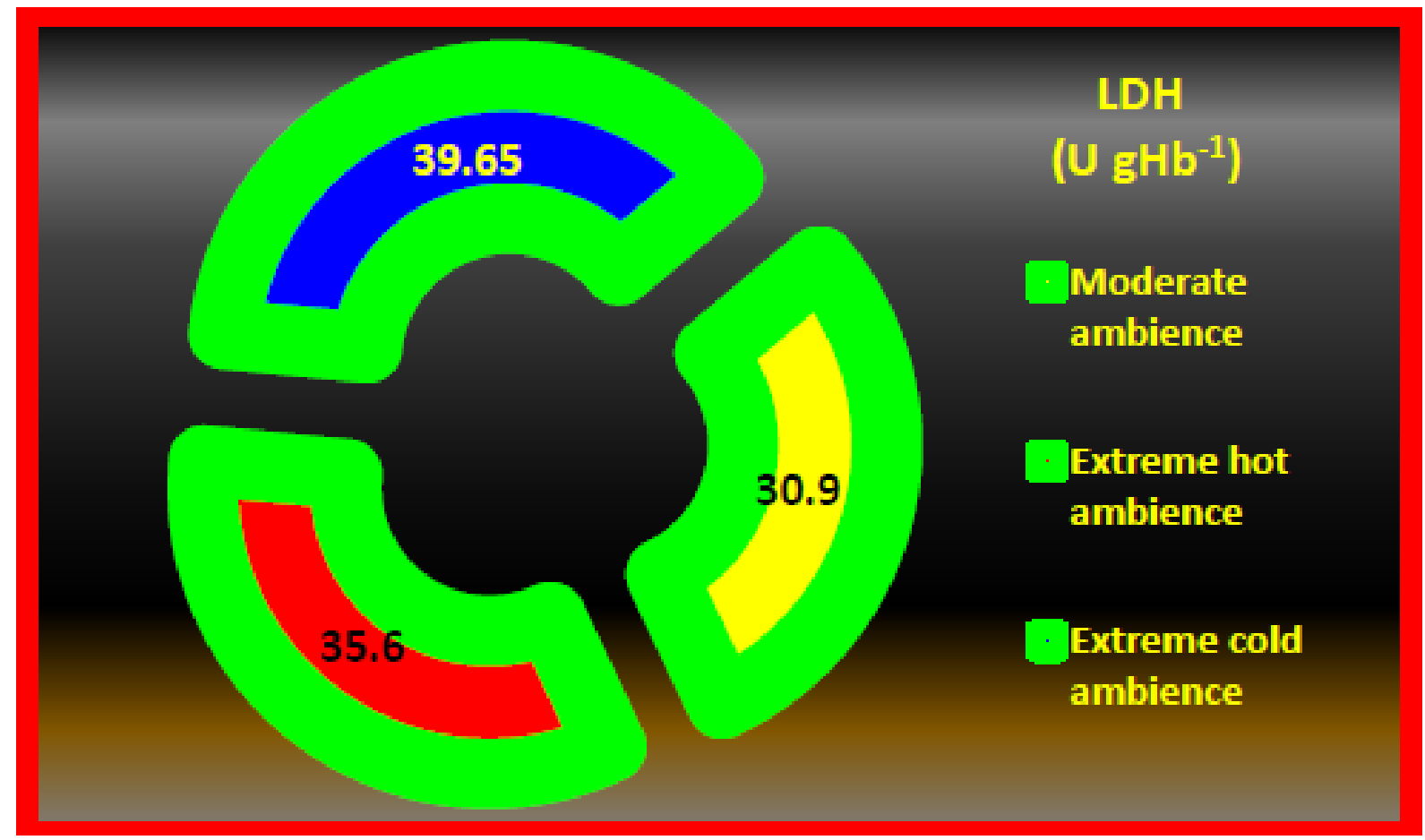

Fig.4 Mean changes in lactate dehydrogenase (U gHb-1, LDH) values according to sex and age groups in the erythrocytes of Marwari sheep during extreme ambiences

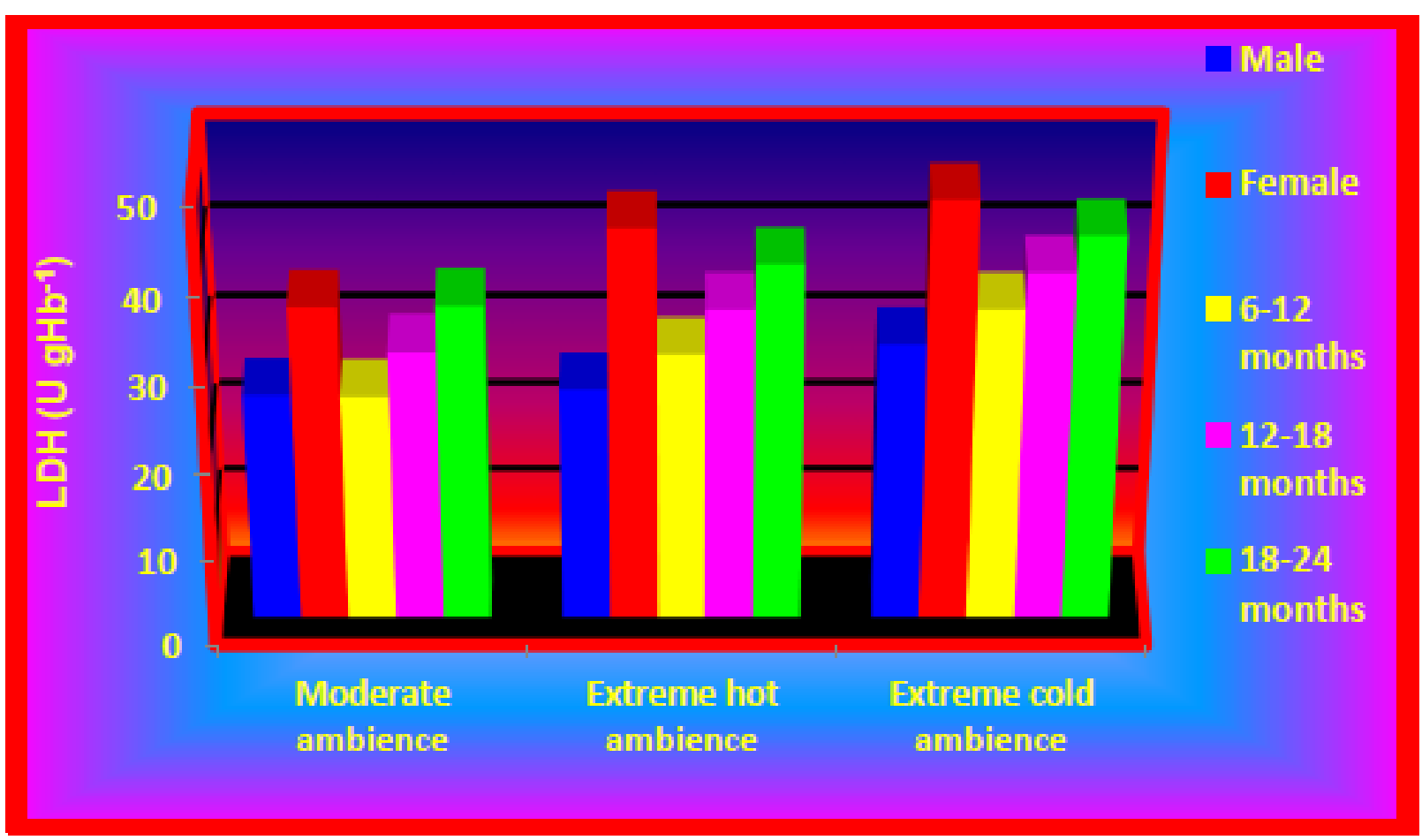




\section{Techniques}

Physical restraint by stockman includes:

- Halter

- Nose grip (fingers or nose tongs)

- Tail elevation

- Skin grip of crural fold

If you do not have a halter or a nose holder the best way to hold a large ruminant is to take a firm grip of the nostril using the thumb and forefinger of one hand while holding the horn or the ear with the other hand (Fig. 5).

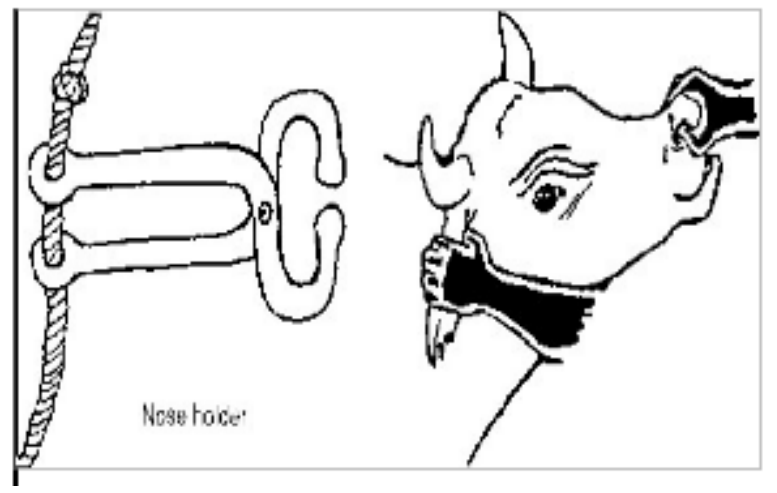

Fig.5 Nose holder

\section{Haltering large ruminants}

- Animals need to be halter-trained and this is best done when they are young so that they are accustomed to the halter.

- When a halter is used on an animal talk to the animal to encourage it to move.

- Hold the halter no more than $20 \mathrm{~cm}$ from the animal cheek and walk close to its neck (Fig. $6)$.

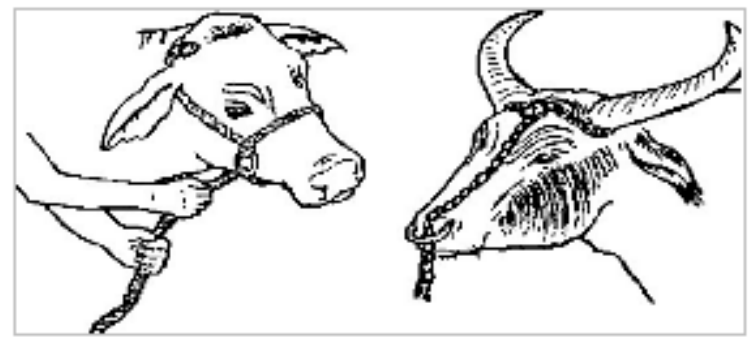

Fig.6 Haltering large ruminants

\section{Casting or throwing cattle and buffalo}

If you do not have a crush and you want to trim the hooves of an animal, it will be necessary for you to cast (throw down) the animal. To do this you will need:

- A halter for the head. 
- Two people to help you.

- Ten to twelve metres of strong rope.

- A place where it is safe to throw the animal, where the soil is soft or covered with straw.

First halter the animal then tie the long rope around it as shown in the illustration below. Have one person to hold the halter while the other joins you and pulls the rope. The animal will collapse onto the floor and your helper must immediately put his knee on its neck and his hand on the animal's head to prevent it from rising.

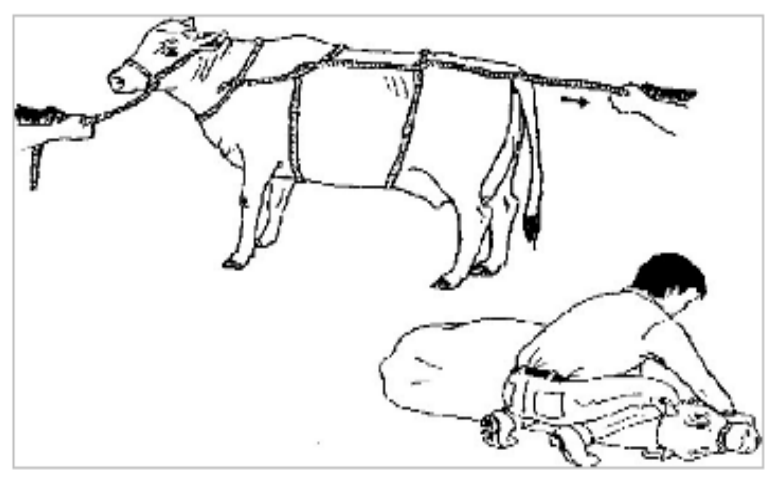

Fig.7 Casting or throwing cattle and buffalo

Do not leave the animal down for a long time as bloat may develop. Remember when casting animals that both the animal and people can get injured so try to do it safely (Fig. 7).

This could be the probable cause of higher LDH concentrations during hot and cold ambiences. The sex and age effects were significant $(p \leq 0.05)$ in moderate, extreme hot and cold ambiences (Fig. 4). The mean values were significantly $(p \leq 0.05)$ higher in female animals than male animals in all the ambiences. Age effect showed a significant $(\mathrm{p} \leq 0.05)$ increase in the mean values being highest in the sheep of 18-24 months of age. Highly significant $(\mathrm{p} \leq 0.01)$ sex and age effects were revealed by analysis of variance. Results corroborated the earlier findings (Chaturvedi, 2011). Sex and age effect on serum LDH activity in goats was also observed by Kour (2010). Lactate dehydrogenase catalyses the reduction of pyruvate in glycolytic cycle and is present in nearly all types of metabolising cells.

\section{References}

Aslan, R., Dundar, Y., Eryavuz, A., Tekerti,
M. and Fidan, F. (2005). G6PD, malondialdehyde and some blood parameters in lambs in relation to environment. Indian Vet. J. 82: 145147.

Chaturvedi, M. (2011). Free radical scavengers and associated analytes in erythrocytes of Marwari goat during extreme ambiences. M.V.Sc. thesis in Veterinary Physiology, college of Veterinary and Animal Science, Bikaner and submitted to Rajasthan University of Veterinary and Animal Science, Bikaner, Rajasthan.

Duncan, D.B. (1955). Multiple range and multiple F tests. Biomet. 11:1-42.

Eguinoa, P., Brocklehurst, S., Arana, A., Mendizabal, J.A., Vernon, R.G. and Purroy, A. (2003). Lipogenic enzyme activities in different adipose depots of Pirenaican and Holstein bulls and heifers taking into account adipocyte size. J. Anim. Sci. 81(2):432-440. 
Ercal,N., Aykin-Burns, N., Gurer-Orhan, H. and McDonald, J.D. (2002). Oxidative Stress in a phenylketonuria animal model. Free Radic. Biol. Med. 32(9):906-911.

Gutierrez, L.L.P., Mazzotti, N.G., Araujo, A.S.R., Klipel, R.B., Fernandes, T.R.G., Llesuy, S.F. and Bello-Klein, A. (2006). Peripheral markers of oxidative stress in chronic mercuric chloride intoxication. Braz. J. Med. Biol. Res. 39(6):767-772.

Jovanovic, P., Zoric, L., Stefanovic, I., Dzunic, B., Djordjevic-Jocic, J., Radenkovic, M. and Jovanovic, M. (2010). Lactate dehydrogenase and oxidative stress activity in primary open-angle glaucoma aqueous humour. Bosn. J. Basic Med. Sci. 10(1): 83-88.

Kaps, M. and Lamberson, W.R. (2004). Biostatics for animal science. CABI Publishing. Oxford shire. pp: 36-270.

Kataria, N. and Kataria, A.K. (2005). A pscychophysiological approach to alleviate stress in cattle. Indian Cow. 2(6):2-5.

Kempel, L.J., Wang, M., Fei, R., Godwin, I.R., McFarlane, J.R. and Agar, N.S. (1999). Erythrocyte metabolism in foetal sheep. Small Ruminant Res. 34(1):27-31.

Kour, G. (2010). Ambient temperature associated variations in serum enzymes and metabolites of hepatic functions in Marwari goat. M.V.Sc. Thesis submitted to SK RAU, Bikaner.

Nesse, R.M. and William, G.C. (1998). Evolution and the origins of disease. Sci. Am. 279(5):86-93.

Ozturk, O. and Gumuşlu, S. (2004). Agerelated changes of antioxidant enzyme activities, glutathione status and lipid peroxidation in rat erythrocytes after heat stress. Life Sci. 75(13):1551-1565.

Piccione, G., Borruso, M., Giannetto, C., Morgante, M. and Giudice, E. (2007). Assessment of oxidative stress in dry and lactating cows. Acta Agric. Scand A. 57:101-104.

Roley, M.J. and Loegering, D.J. (1999). Free Radic. Biol. Med. 27:1455. (Cited from Aslan et al., 2005).

Yagi, K. (1988). Glycolytic enzyme activity and intermediate concentrations in Theileria sergenti-parasitized bovine erythrocytes. Jpn. J. Vet. Sci. 50(2):425431.

\section{How to cite this article:}

Deeksha and Nalini Kataria. 2019. Appraisal of Antioxidative Strategies in the Erythrocytes of Marwari Sheep during Extreme Ambiences. Int.J.Curr.Microbiol.App.Sci. 8(02): 636-643. doi: https://doi.org/10.20546/ijcmas.2019.802.072 